\title{
GESTOS DE LEITURA E ESCRITA DISCURSIVA DE MEMES: EFEITOS DO DIGITAL EM UMA ESCOLA PÚBLICA DO CAMPO
}

\author{
MEME DISCURSIVE READING AND WRITING GESTURES: DIGITAL EFFECTS IN A RURAL \\ PUBLIC SCHOOL
}

\author{
Flávia Ferreira Santana ${ }^{1}$, Maristela Cury Sarian ${ }^{2}$ \\ ${ }^{1}$ Secretaria de Estado da Educação (SEDUC-GO); Secretaria Municipal de Educação (SMEC-Baliza), \\ Baliza, GO, Brasil \\ flavia.santana@unemat.br; \\ ${ }^{2}$ Universidade do Estado de Mato Grosso (UNEMAT), Cáceres, MT, Brasil \\ maristelasarian@unemat.br
}

Recebido em 25 nov. 2019

Aceito em 23 dez. 2019

Resumo: Este trabalho tem por objetivo colocar em evidência um processo de práticas de leitura de memes, desenvolvido sob forma de intervenção pedagógica, com alunos do 9o ano do Ensino Fundamental de uma escola pública, no campo, no município de Baliza-GO, no ano de 2018, em cumprimento a uma das etapas do Programa de Mestrado Profissional em Letras - Profletras, ofertado na Unemat/Cáceres. Daremos visibilidade à produção de práticas polêmicas das maneiras de ler (PÊCHEUX, 2010), por meio das quais criamos as condições para que os alunos realizassem gestos de interpretação em diferentes materialidades significantes, filiadas à discursividade do eletrônico. (ORLANDI, 2013). Como uma entrada possível para o estabelecimento do jogo da paráfrase e da polissemia, de maneira a desestabilizar os sentidos que circulam como evidentes sobre leitura, escrita e TICs na escola, objetivamos romper com os sentidos de leitura parafrástica sedimentados no entremeio institucional/digital e instaurar a constituição de práticas de autoria em sala de aula. A partir de um trabalho sustentado na contradição constitutiva dos processos de textualização de memes, em que o verbal e o não-verbal contraditoriamente se imbricam (LAGAZZI, 2017), foram produzidas as condições para desestabilizar o discurso autoritário (ORLANDI, 2015) em funcionamento na escola, por meio da entrada das discursividades contemporâneo-digitais, em seu caráter material, significadas como uma possibilidade de ressignificar o ensino-aprendizagem de língua portuguesa.

Palavras-chave: Discurso. Tecnologias de escrita. Paráfrase. Polissemia. Discursividades digitais.

\begin{abstract}
The purpose of this work is to bring to the forefront the production process of discursive reading of memes developed under pedagogical intervention with 9th-grade students in a public rural elementary school in the municipality of Baliza, State of Goiás, in 2018 in fulfilling one of the stages of the Professional Master's Degree Program in Languages - PROFLETRAS offered at the Mato Grosso State University (UNEMAT) in the city of Cáceres. Affiliated with the Discourse Analysis by Pêcheux and Orlandi, this paper sheds light on the introduction of the practice of meme reading, creating conditions for the students to carry out interpreting gestures in different significant materialities, different writing materialities, and in the electronic discourse materiality (ORLANDI, 2013). As a possible path to establish the game of paraphrase and polysemy to destabilize the meanings circulating as evident on the reading, writing and CITs at school, we aimed to break with the paraphrastic reading settled in the institutional/digital midst and establishing polysemic reading and authorship practices in the classroom. Based on a work grounded on the constitutive contradiction of meme textualization processes, in which the verbal and non-verbal are contradictorily interwoven (LAGAZZI, 2017), we created conditions to break through authorship gestures in the classroom, destabilizing the authoritarian discourse at work in the school by introducing contemporary digital discursivities in their material character, signifying a possibility to resignify Portuguese language teaching and learning practices.
\end{abstract}

Keywords: Discourse. Writing technologies. Paraphrase. Polysemy. Digital discursivities. 


\section{INTRODUÇÃO}

Nosso objetivo neste artigo é dar visibilidade a um processo de instauração de práticas polêmicas de leitura do arquivo digital em sala de aula, sustentadas na Análise de Discurso materialista, pela qual entendemos ser possível criar as condições de constituição da autoria, no movimento das redes de sentidos que desloca o sujeito de enunciador a autor (ORLANDI, 2012a), a partir da materialidade do discurso digital.

Por essa razão, a construção do arquivo de leitura é ponto nodal em nosso trabalho, por meio do qual objetivamos mobilizar a "materialidade do arquivo" (GUILHAUMOU; MALDIDIER, 2010, p. 174), possibilitando o trabalho do arquivo, ou seja, "aquilo que faz com que ele signifique de um modo e não de outro". (DIAS, 2014, p. 8).

Para tal, elegemos uma atividade realizada ao longo de nosso projeto de intervenção, a partir da qual objetivamos colocar em evidência a relação dos alunos com a materialidade digital em nossa sala de aula, desestabilizar os sentidos que circulam como evidentes sobre a leitura de memes, dando visibilidade aos processos de constituição, formulação e circulação de sentidos. (ORLANDI, 2012b).

Como efeito desse processo, indicamos o modo pelo qual se dá, no trabalho com essa textualidade, o batimento entre a paráfrase e a polissemia na produção de sujeitos e sentidos em nossa sala de aula.

\section{DAS LAN HOUSES MÓVEIS À REDE CEOAP MEMES: UMA VIA PARA A LEITURA NA MATERIALIDADE DIGITAL}

A chegada da internet por vias não institucionais, em 2017, no Assentamento Oziel Alves Pereira, no município de Baliza, estado de Goiás, onde se localiza a escola em que desenvolvemos o projeto, fez com que muitos alunos adquirissem aparelho celular, embora o acesso à internet fosse restrito aos funcionários da escola, um gesto que lemos como um efeito do discurso da conectividade (DIAS, 2018) em funcionamento nessas condições de produção.

Tínhamos, assim, as condições mínimas, do ponto de vista técnico, para trabalharmos com as materialidades digitais em sala de aula, sobretudo, na 
modalidade online. Contudo, o que nos motivou a investir nesse trabalho, fortemente filiado ao digital, foi não só nosso processo de identificação com essas práticas de ensino e a nossa compreensão sobre a produtividade de realizar um trabalho em que se dá consequência à forma material do digital, mas, sobretudo, a necessidade de se romper com as injunções institucionais que estavam funcionando em distintas direções, no que se refere às interdições ao digital, pois, mesmo a sociedade contemporânea sendo tomada por uma profusão de novas discursividades, sobretudo digitais, não significa que estas discursividades e o digital têm uma entrada significativa na escola.

Orlandi (2001) chama a atenção para o fato de que, na escola, em se tratando do enfoque que se dá ao digital, o que temos é uma reiteração dos mesmos espaços do dizer, quando o fundamental, segundo Dias (2014), seria desestabilizar o enfoque conteudista, como forma possível de mudar as práticas, sem as quais não se muda a abordagem dos instrumentos.

É necessário, portanto, desestabilizar o discurso autoritário em funcionamento na instituição escolar, "aquele em que a polissemia é contida, o referente está apagado pela relação de linguagem que se estabelece e o locutor se coloca como agente exclusivo, apagando também a relação com o interlocutor" (ORLANDI, 2015, p. 85), para que outros sentidos sejam possíveis e o sujeito professor tenha condições de exercitar outras práticas de leitura, a ponto de compreender que, da forma como o digital está significado na sociedade, seu funcionamento é ideológico. (DIAS, 2014). Como exemplo desse funcionamento, podemos exemplificar o apagamento do digital como "tecnologia da escrita" (ORLANDI, 2009a p. 63), como "uma técnica da escritura, introduzindo procedimentos novos de escrita e leitura" (DIAS, 2009, p. 12), a qual o aluno está exposto e pela qual ele se expõe, a nosso ver, se coloca como possibilidade de produzirmos uma prática que faça sentido para o aluno, já que o espaço escolar é um lugar de constituição dos sujeitos e dos sentidos.

Por essas razões, colocamos em evidência, desde o início do processo, a forma material meme como nosso objeto de trabalho, pois, enquanto a escola faz "um esforço de evitar o corpo das palavras, suas ambiguidades, equívocos e contradições" (ORLANDI, 2013, p. 9), nós, a contrapelo, estaríamos nos expondo à opacidade da linguagem verbal e não-verbal, firmando a nossa compreensão de 
leitura enquanto "prática simbólica como prática do corpo e que se corporifica no textual". (ORLANDI, 2012b, p. 10).

Vale ressaltar que acreditamos ser possível fazer um trabalho significativo sem a utilização das TICs, entretanto, ao agregarmos as discursividades digitais em nossas aulas, os efeitos de sentidos foram ainda mais significativos, pela força do digital na constituição dos sujeitos e dos sentidos na contemporaneidade. Conforme aponta Dias (2014, p. 12), "o sujeito-professor encontra sujeitos-alunos cada vez mais identificados em seus processos de subjetivação aos sentidos da mobilidade, que se define, na sociedade digital, pela conectividade", embora também compreendamos que os jovens, por terem nascido com a internet e serem significados como nativos digitais, não podem ser significados na lógica opositivadisjuntiva (PÊCHEUX, 2015) que homogeneíza e categoriza sujeitos e sentidos.

Consideramos, assim, o trabalho com memes produtivo para praticarmos formas de leituras polissêmicas, principalmente as que vão se (re)configurando na materialidade digital, pois permite "a compreensão dessa outra forma de leitura, que é a leitura em série, que se naturaliza em nosso cotidiano pelas tecnologias digitais, leitura em smarthphones por meio de aplicativos (Whatsapp, Facebook, Instagran, Twitter) e que está ligada à 'cultura das séries'”. (DIAS, 2019, no prelo).

Dentre os materiais sobre os quais nos debruçamos a fim de compreender discursivamente a textualidade com a qual trabalhamos, destacamos a compreensão de Coelho (2014, p. 19), para quem "a criação de um meme é um gesto de interpretação frente à memória metálica, filiado à memória discursiva da chamada cultura dos memes". Já Dias (2019, no prelo) compreende o meme como "forma material do discurso digital" que pode se textualizar de distintas maneiras, atravessadas pelo funcionamento da repetição, elemento que garante sua textualidade pela aderência dos efeitos de "algo que se repete e que se propaga, em um estado de constante replicação". (COELHO, 2014, p. 9). A autora complementa afirmando que o meme também pode se manter por seu efeito de série, pelo jogo da repetição que institui, por meio de compartilhamentos, curtidas e pela variedade do sentido dos elementos repetíveis, que permite uma regularização do dizer no interior de uma variação regulada.

Ao mobilizarmos sua composição de diferentes materialidades significantes, abrimos possibilidades para o trabalho com outros objetos simbólicos, permitindo 
que os alunos compreendessem que a constituição dos sentidos se dá na diversidade das formas materiais que se imbricam na textualização de um arquivo, e não somente em/por textos escritos, predominantemente verbais e longos, legitimados pela escola e por seus instrumentos linguísticos:

Não há um sistema de signos só, mas muitos. Porque há muitos modos de significar e a matéria significante tem plasticidade, é plural. Como os sentidos não são indiferentes à matéria significante, a relação do homem com os sentidos se exerce em diferentes materialidades, em processos de significação diversos: pintura, imagem, música, escultura, escrita etc. A matéria significante - e/ou a sua percepção - afeta o gesto de interpretação, dá uma forma a ele. (ORLANDI, 1996, p. 12).

Com essa compreensão, a seguir, apresentaremos brevemente as condições de produção que ensejaram a realização de uma atividade e seus efeitos, acompanhada de nosso gesto interpretativo.

\section{SUJEITOS E SENTIDOS NA DISPERSÃO DA REDE: UMA VIA PARA A DESESTABILIZAÇÃO DO ARQUIVO}

A partir do registro e das discussões sobre as regularidades dos memes trabalhados nas aulas anteriores ${ }^{1}$, solicitamos aos alunos que realizassem uma atividade de pesquisa sobre memes, em grupo, como um primeiro movimento de saída da identificação institucional do arquivo para a dispersão do arquivo na rede, mergulho arquivístico fundamental que coloca sujeitos e sentidos em relação com a materialidade dos textos, na discursividade digital. (DIAS, 2014).

Durante a pesquisa, em aparelhos celulares ${ }^{2}$ em sala de aula, solicitamos que cada grupo baixasse um meme de uma temática com a qual se identificasse, para que pudéssemos fazer a impressão dos textos, a serem colados em cartolina.

$\mathrm{Na}$ sequência, solicitamos que os grupos elaborassem cartazes, nos quais agregaram uma noção de meme, acompanhada de exemplos de suas possíveis

\footnotetext{
${ }^{1}$ Como entrada do processo de leitura, desenvolvemos, anteriormente a esta, algumas atividades de leitura, tais como a de 03 memes-vídeos: "Levanta a cabeça, princesa"; "Que tiro foi esse?" e "Nunca nem vi", acompanhados de algumas de suas séries. Realizamos também uma atividade de leitura de cores, a fim de desestabilizar o sentido de texto escrito, verbal e longo, pela "deslinearização da imagem pela remissão do intradiscurso ao interdiscurso". (LAGAZZI, 2013, p. 105). A pedido dos alunos, retomamos a leitura de alguns memes até chegarmos nesta atividade que ora recortamos.

${ }_{2}^{2}$ Para o desenvolvimento do projeto, nossa proposta era de que os alunos trabalhassem utilizando o celular e aqueles que, porventura, não o possuíssem, poderiam utilizar dois computadores de mesa que a escola disponibilizou para o projeto. Destacamos que, pelo efeito do discurso da conectividade que significa smartphones como objetos de inclusão e status, em processos sociais numa sociedade dividida (DIAS, 2018), nenhum aluno quis usar as outras máquinas disponíveis.
} 
textualizações, com vistas a analisarmos como os alunos estavam se relacionando com essa forma material e suas especificidades. Na sequência, compartilharam suas produções com os colegas, por meio de uma socialização em sala de aula. Dentre os cartazes produzidos, recortamos, para esta análise, um material elaborado por um dos grupos, apresentado abaixo:

Figura 1 - Meme selecionado e suas definições representados no cartaz

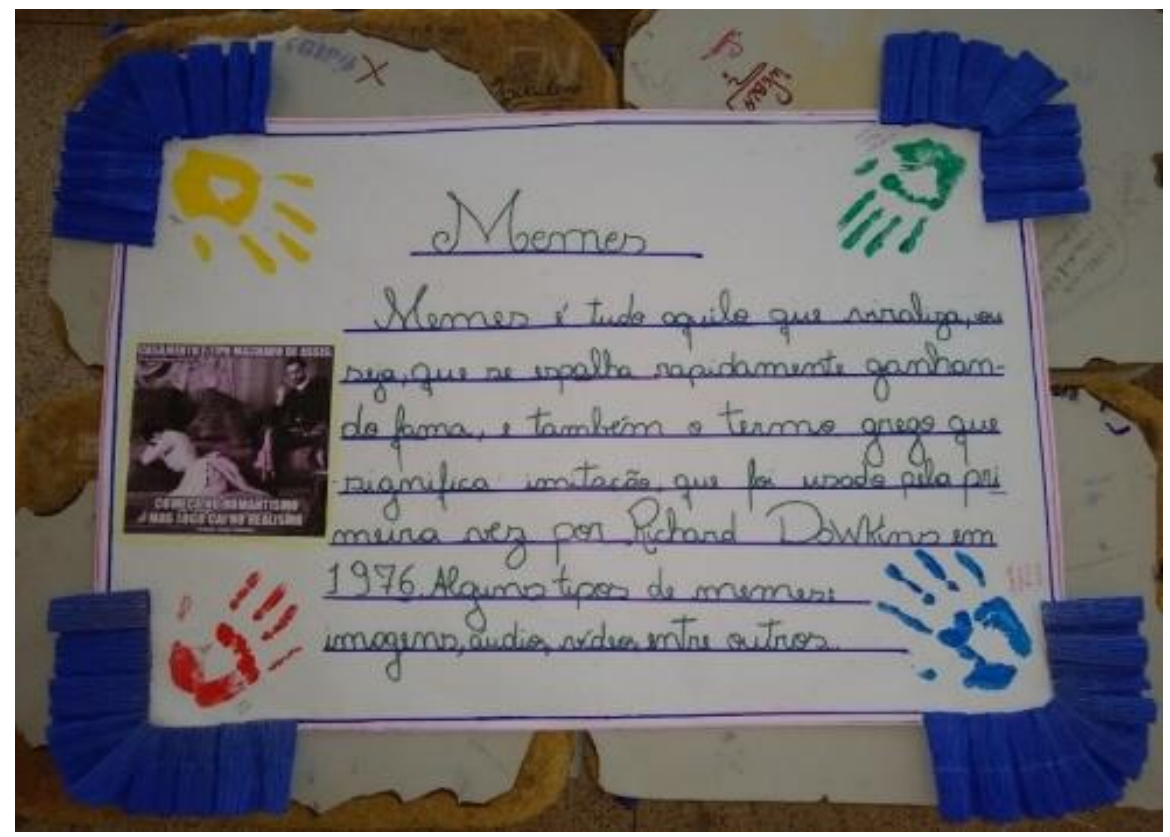

Fonte: Arquivo da autora.

As alunas do grupo se colocaram à frente da sala, portando o cartaz, afetadas pelas coerções inerentes à fala pública, produzindo uma exposição com efeito de tensão, projetando, nesse ato de fala, a imagem de insegurança (SOUZA, 2014), próxima de uma fala mecânica, engessada, porque tensionada pelas relações de força em movimento nas condições de produção de sala de aula. É preciso considerar que falar da posição-sujeito aluno para o sujeito professor é falar da posição de quem é significado como aquele que não sabe para aquele que sabe; é expor-se ao público e expor-se a essa posição, num jogo de formações imaginárias, "jogo imaginário que preside a troca de palavras". (ORLANDI, 2015a, p. 38).

No que tange à compreensão de meme materializada no cartaz, ressaltamos que as alunas registraram definições trabalhadas em sala de aula, como efeito do conteúdo abordado ao longo do projeto, ressoando, nessas formulações, as definições de Coelho $(2014$, p. 98): 
O termo 'meme' foi usado pela primeira vez na obra 'O Gene Egoísta' de Richard Dawkins. Em sua obra, Dawkins fez uma comparação entre informação genética e elementos que ele chama de culturais, classificando ambos como 'replicadores', ou seja, capazes de multiplicar e propagar, gerando assim elementos com as mesmas características, que por sua vez repetirão o processo em um ciclo perpétuo.

Para lançarmos nossos gestos de interpretação ao meme escolhido, apresentamos a Figura 2:

Figura 2 - Meme "Romantismo - Realismo"3

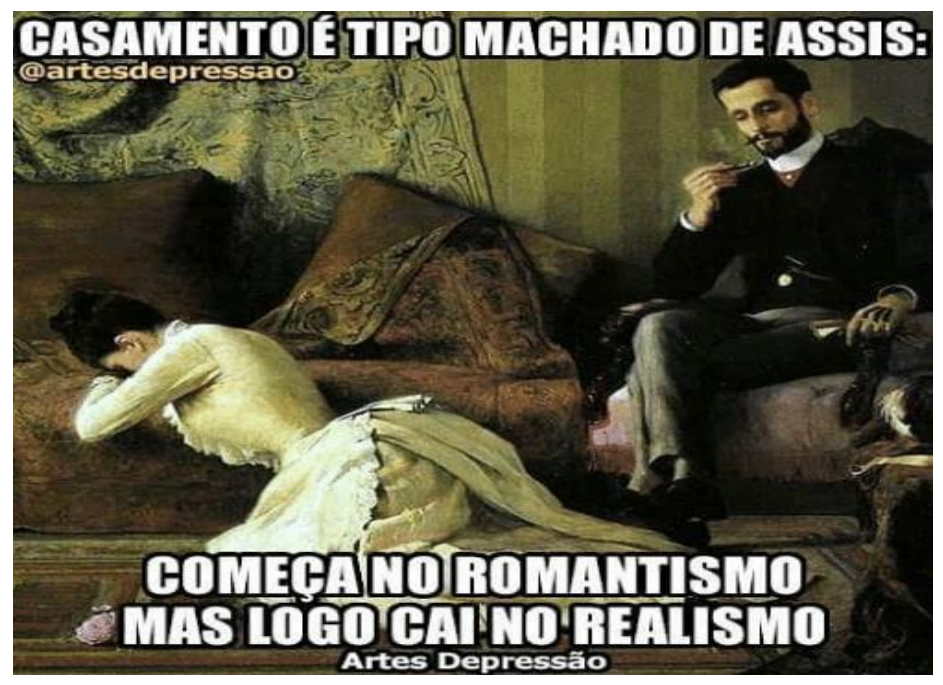

Fonte: Página Artes Depressão ${ }^{4}$.

Durante a exposição sobre a forma material meme, as componentes do grupo formularam seus gestos de interpretação, que organizamos em sequências discursivas, apresentadas a seguir:

SD1 - A escrita de nosso meme mostra que, com o tempo de casado, o Romantismo vai se acabando.

SD2 - A imagem mostra que a mulher é a que mais sofre numa relação, embora ambas as partes podem ser consideradas românticas.

SD3 - Na maioria das vezes as mulheres são mais carinhosas e prestativas, já os homens se deixam levar pelo orgulho, deixando de lado o romantismo.

\footnotetext{
${ }^{3}$ Pintura intitulada Arrufos ou (Dramas do casamento), datada do ano de 1887, cuja autoria remete ao artista mineiro Belmiro de Almeida (1858-1935). Considerada pelo renomado crítico de arte GonzagaDuque (1863-1911) como inovadora, por ser a primeira obra (em sua concepção) a romper com tradição da pintura de história, a tela constitui um marco para a arte brasileira ao representar um acontecimento doméstico e trivial. (CAPICHONI, 2016).

${ }^{4}$ Disponível em: https://www.facebook.com/ArtesDepressao/. Acesso em: 24 nov. 2019.
} 
SD4 - No Romantismo enxergamos que tudo é perfeito e durará para sempre.

SD5 - O Realismo mostra fatos reais onde nem tudo é perfeito.

SD6 - E com o passar do tempo o amor pode ir se desgastando, Machado de Assis foi um dos principais nomes do Realismo brasileiro.

SD7 - Casamento é tipo Machado de Assis, começa no Romantismo, mas logo cai no Realismo.

Ao passarmos à análise das sequências discursivas, é importante destacar que não há nem boa nem má leitura (ORLANDI, 2009b), mas gestos particulares de leitura em que sujeitos e sentidos, por suas condições de produção, se constituem concomitantemente. (ORLANDI, 2015).

Tomando a SD1 "A escrita do nosso meme mostra que com o passar do tempo o Romantismo vai se acabando" em relação à SD2 "A imagem mostra que a mulher é a que mais sofre numa relação, embora ambas as partes podem ser consideradas românticas ${ }^{, 5}$, compreendemos, desses gestos de interpretação, o sentido de texto sedimentado na ilusão da transparência da linguagem, enquanto "unidade empírica" (ORLANDI, 2012b, p. 64), como se os sentidos já estivessem fixados a priori, na essência das palavras e das imagens, num apagamento da "relação contraditória entre paráfrase e polissemia como eixo que estrutura o funcionamento da linguagem" (ORLANDI, 1998, p. 14); sentidos que se filiam às formações discursivas de um discurso autoritário, que ancora 0 trabalho com a língua na escola, sustentado na leitura de conteúdo. (ORLANDI, 2015).

A sobreposição do verbal ao não-verbal na história da sociedade ocidental (ORLANDI, 1995) faz incidir, na SD1, o efeito de memória da escrita, da cultura do manuscrito (ORLANDI, 2012b), inscrevendo esse dizer na discursividade da escrita, como efeito da "produção de conhecimento linguístico e de sua entrada na escola pela língua escrita" (ORLANDI, 1995, p. 69), pelo funcionamento da memória institucional que alimenta e estabiliza a ilusão de literalidade.

Gallo (1989, p. 69), em referência aos discursos legitimados na escola, afirma que essa instituição "apresentará, aos estudantes, o Discurso Escrito, como modelar, e sua forma como Normativa. Essa prática pedagógica estará legitimando,

${ }^{5}$ Todos os grifos nas sequências discursivas são nossos. 
mais uma vez, esse discurso, que, por isso mesmo, produz um sentido único e desambigüizado", efeito de evidência sobre a qual precisamos fazer trabalhar a produção interpretativa (ORLANDI, 2012b), opacificando textos e sentidos.

Essas duas sequências discursivas colocam à mostra a disjunção do verbal - "a escrita mostra" (SD1) - do não-verbal - "a imagem mostra" (SD2), interpretados de forma independente e opositiva, e não em uma relação de composição, no sentido em que formula Lagazzi (2017, p. 35), ou numa "relação pela contradição entre as diferentes estruturas materiais constitutivamente falhas e incompletas". Gestos que nos levam a compreender que "saber como os discursos funcionam é colocar-se na encruzilhada de um duplo jogo da memória: o da memória institucional que estabiliza, cristaliza, e, ao mesmo tempo, o da memória constituída pelo esquecimento que é o que torna possível o diferente, a ruptura, o outro". (ORLANDI, 2015, p. 8).

Assim como há a sobredeterminação do verbal sobre o não-verbal, vemos circular a sobredeterminação das textualidades do discurso da escrita sobre as textualidades do discurso do digital na escola, isto é, aquelas que estão fora da chancela dos instrumentos linguísticos e das políticas públicas, visto que não têm status de textos a serem lidos e escritos no ambiente escolar, porque não são constitutivas da memória de arquivo. (HASHIGUTI, 2009).

A escolha da temática do meme no arquivo recortado também chama a atenção para o fato de o grupo ser formado por alunas adolescentes, o que pode significar o funcionamento de uma formação discursiva, de uma memória sobre relacionamentos heteronormativos sedimentada no processo contraditório de identificação da mulher com um sentido idealizado: "no Romantismo enxergamos que tudo é perfeito e durará para sempre" (SD4), fazendo emergir as compreensões de que "a imagem mostra que a mulher é a que mais sofre numa relação, embora ambas as partes podem ser consideradas românticas" (SD2) e "na maioria das vezes as mulheres são mais carinhosas e prestativas, já os homens se deixam levar pelo orgulho, deixando de lado o romantismo" (SD3).

Essas formulações reproduzem o funcionamento do discurso machistapatriarcal e atualizam a memória discursiva que institui sentidos estabilizados para as relações amorosas - "o romantismo vai se acabando" (SD1), para o afeto "ambas as partes podem ser consideradas românticas" (SD2) e para as posições- 
sujeito homem e mulher - "as mulheres são mais carinhosas e prestativas, já os homens se deixam levar pelo orgulho" (SD3).

Contraditoriamente - e aqui tomamos o sentido de contradição de Pêcheux (1977; 1990) - as alunas projetam sentidos menos idealizados de uma relação amorosa, materializados em "e com o passar do tempo o amor pode ir se desgastando, Machado de Assis foi um dos principais nomes do Realismo brasileiro" (SD6) e "Casamento é tipo Machado de Assis, começa no Romantismo, mas logo cai no Realismo" (SD7).

Ao jogarem com os significantes "Romantismo" e "Realismo", as alunas imprimem um sentido estabilizado para as correntes literárias, tradicionalmente significadas em oposição, "no Romantismo enxergamos que tudo é perfeito e durará para sempre (SD4) e "o Realismo mostra fatos reais onde nem tudo é perfeito" (SD5). Vemos o atravessamento de uma filiação dos sentidos de "Romantismo" ao amor romântico, um sentido dominante desse movimento literário ensinado na escola, em oposição ao "Realismo", ancorado no sentido de realidade, pois as alunas ficam nos limites de uma leitura parafrástica, em que fica atestada "a insuficiência da oposição como movimento do sujeito para deslocar as interpretações estabilizadas como verdades". (LAGAZZI, 2015, p. 52).

Pelo funcionamento do discurso do consenso, esses gestos de interpretação se naturalizam nas formulações visuais intradiscursivas, projetando sentidos socialmente estabilizados para os corpos masculinos e femininos diferentemente fletidos. Formulações visuais que apontam para uma divisão de sentidos que, pela materialidade do corpo da mulher, debruçado sobre a poltrona, coloca o dito, pelo corpo flexionado, numa relação de sentidos de oposição com o não-dito (LAGAZZI, 2015), pelo corpo do homem sentado, memória discursiva que se atualiza pelo deslize nas formulações das alunas, fazendo irromper um sentido de homem que se relaciona contraditoriamente com a demonstração de sentimentos, pois "embora ambas as partes podem ser consideradas românticas" (SD2), "os homens se deixam levar pelo orgulho" (SD3).

Sentidos que acabam por inscrever, pela repetição materializada nos corpos, a mulher em uma região de sentidos de fragilidade, sofrimento e subalternização, ao passo que os sentidos reproduzidos para o homem ancoram-no na racionalidade, indiferença e introspecção. Um efeito de sentido de um humanismo paradoxal, que 
atravessa os processos de identificação das alunas, atualizando o já-dito legitimado que opõe o ser homem ao ser mulher, posições significadas por relações de força que estabilizam efeitos de sínteses-consensos, conciliando diferenças que precisam ser trabalhadas, e não encobertas. (LAGAZZI, 2015).

Gestos de interpretação que silenciam o jogo de linguagem em que o verbal e o visual se imbricam na composição desse arquivo, apagando as especificidades de sua constituição, formulação e circulação na materialidade digital, nos dando pistas do quanto esse processo de instaurar práticas de leituras polêmicas, que, nesta atividade, instituem um lugar para o verbal na relação com o não-verbal e o digital, é uma forma de resistência simbólica na história (LAGAZZI, 2015), de resistência à uma prática de leitura que não se historiciza e estabiliza sentidos e sujeitos da escolarização, vetando a autoria. Daí a necessidade de "levar em conta a relação do que é dito em um discurso e o que é dito em outro, o que é dito de um modo e o que é dito de outro, procurando 'escutar' a presença do não dito no que é dito: presença produzida por uma ausência necessária". (ORLANDI, 1998, p. 10).

Com a realização dessa atividade, foi possível colocar em evidência o modo pelo qual se dá o funcionamento da memória discursiva na constituição dos memes, no batimento entre a memória institucional em funcionamento na escola, que alimenta a ilusão de literalidade, e a memória metálica, base do digital, que se faz pelo acúmulo, pela repetição, mas que se historiciza, "pelos efeitos do simbólico e da história" (ORLANDI, 1998, p. 11), o que demanda compreender "a ordem do digital, ou seja, entender como o simbólico em sua relação com o político determina sentidos, mas também os sujeitos". (DIAS, 2018, p. 63).

Nessa direção, podemos afirmar que foram instauradas, nessas práticas, 0 "furo" e a "resistência" (ORLANDI, 2018, p. 14) pelo funcionamento da contradição no batimento memória metálica - memória discursiva, pois

entre a memória histórica e a memória metálica (efeito de memória), o que estou chamando de memória digital. A memória digital seria, pois, o lugar da contradição, onde a memória escapa à estrutura totalizante da máquina (memória metálica), saindo do espaço da repetição formal se inscreve no funcionamento do interdiscurso (memória discursiva). (DIAS, 2018, p. 104-105, grifo do autor).

Ao mobilizarmos a noção de discurso como "efeito de sentidos entre locutores" (ORLANDI, 2012b, p. 64), acreditamos ter sido possível mexer nas relações de força que imprimem os sentidos de língua e do digital em funcionamento na escola, na 
"verticalização das posições professor-aluno" (DIAS, 2014, p. 1), desestabilizandoas, porque é próprio do funcionamento do digital, da internet, visto que esta "esburaca as estruturas verticais de poder, pelo menos até o momento em que ela é tomada em sua mobilidade, em sua 'materialidade dispersa' (ORLANDI, 2004), em sua temporalidade, em sua fluidez". (DIAS, 2014, p. 2).

Assim, acreditamos ter criado as condições de deslocar as novas tecnologias e as discursividades contemporâneo-digitais, multifacetadas em sua constituição, da condição de objeto, de repositórios, para tratá-las como tecnologias de escrita, como materialidade aberta ao trabalho do simbólico.

\section{CONSIDERAÇÕES FINAIS}

Esse movimento de análise coloca em evidência o quanto precisamos resistir, no sentido de criar condições para um outro trabalho de leitura e escrita na escola, de modo a dar visibilidade à materialidade da língua inscrita na história e nos distanciar de um discurso autoritário que produz interdições a professores, alunos e ao digital. Daí a necessidade de uma escuta atenta e sensível, que se distancie de uma posição sujeito-leitor empresarial (ORLANDI, 2012b), desejada pela escola e pela sociedade capitalista, e da tomada da palavra de professores e alunos, compreendida como "um ato social com todas as suas implicações: conflitos, reconhecimentos, relações de poder, constituição de identidade, etc". (ORLANDI, 2012a, p. 22).

Não se trata de mera insistência para que o aluno fale, ou de defender o posicionamento de uma suposta igualdade entre professores e alunos em sala de aula, ou seja, não podemos incidir no equívoco da intercambialidade, em que "as posições equivalentes são intercambiáveis, mutuamente substituíveis" (ORLANDI, 1998, p. 17). Para que ambos ocupem suas posições e entrem no jogo simbólico de aprender e ensinar, é preciso a intervenção da reversibilidade (ORLANDI, 1998, p. 17), que "é a possiblidade que a posição-aluno tenha igual legitimidade no processo discursivo em que se confronta com a posição-professor".

Ao mesmo tempo, precisamos ressignificar nossa posição-sujeito professor, nos deslocando do lugar de uma "posição histórica material apagada em função do mecanismo ideológico que produz o efeito referencial, simulando uma relação direta 
entre palavras e coisas" (ORLANDI, 1998, p. 18), para que possamos também ressignificar a posição-sujeito aluno, de modo a criar espaços de autoria para os sujeitos da escolarização.

No que diz respeito aos deslocamentos, possíveis e necessários, à assunção da autoria de professores e alunos, Orlandi (1998, p. 17) enfatiza:

\begin{abstract}
Para mim, ensinar é produzir condições para que o aluno, aprofundando sua posição-aluno, tenha voz para intervir no processo que o colocará futuramente na posição-professor. Para isso ele deverá se confrontar com sua memória e trabalhá-la, a partir de e em confronto com os sentidos produzidos pela posição-professor. É assim que, por seu lado, o professor trabalha sua mediação em relação à posição-aluno. $O$ que deveria ser evitado é justamente o que eu chamaria a 'pretensa' intercambialidade entre aluno e professor, ou seja, o aluno não deve falar da posição-professor e o professor não pode pretender fazê-lo da posição-aluno. Limite imposto pela alteridade: não se pode falar do lugar do outro.
\end{abstract}

A perspectiva discursiva nos permitiu pensar o ensino de língua a partir do discurso, produzindo uma prática distinta da estabilizada, concebendo a linguagem em seu funcionamento, considerando o sujeito em suas condições sócio-históricas. Por essa razão, a participação do aluno em todo o processo foi tão importante, porque estávamos, com esse gesto, acolhendo a capacidade de compreensão do sujeito aluno, investindo, por meio da construção de arquivos, na capacidade desse aluno de construir e de ler arquivos:

É preciso construir condições para, acolhendo sua capacidade simbólica, aumentar a capacidade de compreensão do aprendiz. Ensinar aqui significa trabalhar o efeito-leitor com o próprio aprendiz. $E$ isto visa interferir na imagem que ele tem de texto e de leitura. Para isso é preciso mexer com a capacidade que esse sujeito tem de construir arquivos. Fazer presentes textos que possam ajudá-lo a compreender um texto posto. E isso se faz por uma mexida na relação estrutura/acontecimento. (ORLANDI, 2012b, p. 70-71, grifo do autor).

E como costura de um possível e necessário efeito de fecho, parafraseamos Orlandi (2012b): o que fica desse processo, em nossa prática, é que sujeitos se fazem no movimento de entrega e de resistência, trabalhando suas contradições, constituindo-se em várias formas de sujeito-leitor, e, a partir daí, passando a saborear a leitura, descobrindo que "o real: a gente se depara com ele, dá de encontro com ele" (PÊCHEUX, 2015, p. 29) em algum ponto da travessia. 


\section{REFERÊNCIAS}

CAPICHONI, A. T. De Arrufos a Conciliadora: a construção imagética da família no Brasil na transição do século XIX para o XX. In: XIX ENCONTRO REGIONAL DE HISTÓRIA - ANPUH MG, 19., 2014, Juiz de Fora. Anais [...] Juiz de Fora: UFJF. p. 1-146. Disponível em: http://www.ufjf.br/ppghistoria/files/2016/02/DISSERTA $\mathrm{O}-$ CONCLU_DA-E-CORRIGIDA-Arrufos-ou-adult_rio-Debates-sobre-uma-tela-deBelmiro-de-Almeida.pdf. Acesso em: 16 dez. $20 \overline{19}$.

\section{COELHO, A. L. P. F. Brace Yourselves, memes are coming formação e} divulgação de uma cultura de resistência através de imagens da internet. 2014. Dissertação (Mestrado em Divulgação Científica e Cultural) - Programa de PósGraduação Divulgação Científica e Cultural, Universidade Estadual de Campinas, Campinas, 2014.

DIAS, C. Textualidades seriadas: entre a repetição, a regularização e 0 deslocamento, 2019. No prelo.

DIAS, C. P. A escrita como tecnologia da linguagem. Tecnologias de linguagem e produção do conhecimento, Santa Maria, v. 2, p. 7-17, dez. 2009. (Coleção Hiper Saberes). Disponível em: http://w3.ufsm.br/hipersaberes/volumell/textos_pdf /TXTS_PDF/cristiane_dias.pdf. Acesso em: 20 out. 2017.

DIAS, C. P. Sujeito, sociedade e tecnologia: a discursividade da rede (de sentidos). São Paulo: Hucitec, 2012.

DIAS, C. P. O ensino, a leitura e a escrita: sobre conectividade e mobilidade.

Entremeios: Revista de estudos do discurso, Pouso Alegre, v. 9, p. 1-13, jul., 2014. Disponível em: http://www.entremeios.inf.br/published/198.pdf. Acesso em: 20 abr. 2018.

DIAS, C. P. Análise do discurso digital: sujeito, espaço, memória e arquivo. Campinas: Pontes, 2018.

GALLO, S. M. L. Ensino da língua escrita x ensino do discurso escrito. 1989.

Dissertação (Mestrado em Linguística) - Instituto de Estudos da Linguagem, Universidade Estadual de Campinas, Campinas, 1989.

GUILHAUMOU, J.; MALDIDIER, D. Efeitos do arquivo: a análise do discurso no lado da história. In: ORLANDI, E. P. (org.). Gestos de leitura. 3. ed. Campinas: Editora da UNICAMP, 2010. p. 161-183.

HASHIGUTI, S. T. Nas teias da leitura. In: BOLOGNINI, C. Z.; PFEIFFER, C. R. C.; LAGAZZI-RODRIGUES, S. M. (org.) Práticas de linguagem na escola. Campinas: Mercado das Letras, 2009. p. 10-30.

LAGAZZI, S. M. A imagem do corpo no foco da metáfora e da metonímia. REDISCO - Revista Eletrônica de Estudos do Discurso e do Corpo, Vitória da Conquista, v. 2, n. 1, p. 104-110, 2013. 
LAGAZZI, S. M. A imagem em curso. A memória em pauta. In: TASSO, I.; CAMPOS, J. (org.). Imagem e(m) discurso: a formação das modalidades enunciativas.

Campinas: Pontes, 2015. p. 51-65.

LAGAZZI, S. M. Trajetos do sujeito na composição fílmica. In: FLORES, G. G. B.; NECKEL, N. R. M.; GALLO, S. M. L. (org.). Análise de discurso em rede: cultura e mídia. Campinas: Pontes, 2017. p. 23-39. v. 3.

ORLANDI, E. de L. P. Efeitos do verbal sobre o não-verbal. Rua, Campinas, n. 1, v. 1, p. 35-47, mar. 1995. Disponível em: https://periodicos.sbu.unicamp.br/ojs/ index.php/rua/article/view/8638914/6517. Acesso em: 01 abr. 2018.

ORLANDI, E. de L. P. Interpretação: autoria, leitura e efeitos do trabalho simbólico. Petrópolis: Vozes, 1996.

ORLANDI, E. de L. P. Paráfrase e polissemia a fluidez nos limites do simbólico. Rua [on-line], Campinas, v. 4. n. 1, p. 9-20, 1998. Disponível em: https://periodicos.sbu. unicamp.br/ojs/index.php/rua/article/view/8640626. Acesso em: 5 abr. 2018.

ORLANDI, E. de L. P. O que é linguística? 2. ed. São Paulo: Brasiliense, 2009a.

ORLANDI, E. P. A linguagem e seu funcionamento: as formas do discurso. 5. ed. Campinas: Pontes, 2009b.

ORLANDI, E. de L. P. Discurso e leitura. 9. ed. São Paulo: Cortez, 2012a.

ORLANDI, E. de L. P. Discurso e texto: formulação e circulação de sentidos. 4. ed. Campinas, SP: Pontes Editores, 2012b.

ORLANDI, E. de L. P. Análise de discurso: princípios e procedimentos. 12. ed. Campinas: Pontes, 2015.

ORLANDI, E. de L. P. Prefácio. In: DIAS, C. Análise do discurso digital: sujeito, espaço, memória e arquivo. Campinas: Pontes, 2018. p. 11-18.

PÊCHEUX, M. Remontemos de Foucault a Spinoza. In: BARONAS, R. L. (org.). Análise do discurso: apontamentos para uma história da noção-conceito de formação discursiva. 2. ed. São Carlos: Pedro e João Editores, 2011. p. 177-192. Originalmente publicado em 1977.

PÊCHEUX, M. Ler o arquivo hoje. In: ORLANDI, E. P. (org.). Gestos de leitura. 3. ed. Campinas: Editora da UNICAMP, 2010. p. 49-59.

PÊCHEUX, M. O discurso: estrutura ou acontecimento. Tradução de Eni de L. P. Orlandi. 7. ed. Campinas: Pontes, 2015.

SOUZA, P. de. Sobre o discurso e o sujeito na voz. Língua e instrumentos linguísticos, Campinas, n.34, p.199-211, jul./dez. 2014. 


\section{Sobre as autoras}

\section{Flávia Ferreira Santana}

Possui graduação em Letras - Português e Literatura de Língua Portuguesa (UFMT-2005). Especialização em Metodologia do Ensino Fundamental (CEPAE/UFG-2011) e Mestrado em Letras (PROFLETRAS UNEMAT/CACERES-2019). Tem experiência na área de Letras, com ênfase em Língua Portuguesa. É lotada na rede pública municipal e estadual de educação de Baliza - GO. Atua no Ensino Fundamental e Médio, bem como na formação de professores da Educação Básica.

\section{Maristela Cury Sarian}

É graduada em Letras-Tradutor e Mestre em Estudos Linguísticos pela UNESP/São José do Rio Preto. Doutora em Linguística pela UNICAMP, é professora da Universidade do Estado de Mato Grosso (UNEMAT) Carlos Alberto Reyes Maldonado. Na gestão, atua como Coordenadora do Programa de Mestrado Profissional em Letras - PROFLETRAS ofertado na Unidade Cáceres. Como destaque na pesquisa, coordena, com Claudia Regina Castellanos Pfeiffer (LABEURB/UNICAMP) e Ana Cláudia Fernandes Ferreira (IEL/UNICAMP), a Linha 1 - História das Ideias Linguísticas - do GTAD da ANPOLL. Tem experiência na área de Letras, com ênfase em Linguística, Língua Portuguesa e Estudos da Tradução. 